\title{
Osteoporosis in the age of COVID-19
}

\section{M. Girgis ${ }^{1,2,3} \cdot$ R. J. Clifton-Bligh ${ }^{1,2}$}

Received: 26 March 2020 / Accepted: 6 April 2020/Published online: 28 April 2020

(C) International Osteoporosis Foundation and National Osteoporosis Foundation 2020

\begin{abstract}
As the world grapples with the crisis of COVID-19, established economies and healthcare systems have been brought to their knees. Tough decisions regarding redirection of resources away from the management of conditions deemed "nonessential" are being made. How can we balance urgent resourcing of our acute crisis while not abandoning the real need of patients with osteoporosis? This article offers a few practical solutions.
\end{abstract}

Keywords Osteoporosis $\cdot$ COVID-19 $\cdot$ Fracture $\cdot$ Bisphosphonate $\cdot$ Denosumab $\cdot$ Bone mineral density

"In a crisis, every little thing counts" - Jawaharlal Nehru

As the world grapples with the crisis of COVID-19, this pandemic continues to exceed our worst expectation in terms of the number of lives lost, the human suffering that has ensued and the rapidity at which established economies and healthcare systems have been brought to their knees. At the time of writing, the global death toll stands at more than 127,000 , global economies and labour markets teeter on the edge and health systems in the developed world are forced to make tough decisions regarding re-direction of resources away from the management of conditions deemed "nonessential".

In these unprecedented times, the model of healthcare towards chronic disease may undergo indelible change. Individuals with chronic conditions, such as frail older and immune-compromised members of our community have been advised by their governments to avoid outdoor activity and limit their exposure to large groups of people, including attending hospitals and other centres of healthcare delivery. At the same time, resources will be redirected from chronic

C. M. Girgis

christian.girgis@sydney.edu.au

1 Faculty of Medicine and Health, University of Sydney, Sydney, Australia

2 Department of Endocrinology and Diabetes, Royal North Shore Hospital, St Leonards, Sydney, Australia

3 Department of Endocrinology and Diabetes, Westmead Hospital, Westmead, Sydney, Australia disease care programs to the fight against this rapidly evolving, acute global threat.

Clinical services designed to prevent morbidity and improve functional independence in older people, such as Fracture Liaison Services, will be scaled back, possibly for months, and suspended in their current form. Whilst Telehealth medicine may provide new opportunities [1], clinical decision-making around the assessment and management of osteoporosis, as well as many other chronic conditions, will be impacted.

Osteoporosis kills. Hip fractures remain a catastrophic event with a 1-year mortality of $20 \%$ and are a leading cause of morbidity and loss of functional independence in older members of our society [2,3]. Every year, approximately 740,000 people lose their lives around the world as a result of hip fracture [4]. An estimated 5.8 million disability adjusted life years (DALYs) are lost as a direct result of osteoporotic fracture every year [3]. Expert groups have raised the alarm on the public health emergency of osteoporosis, the reduction in bone density scanning and declining treatment rates amongst patients presenting with fractures [5]. One in 3 men and one in 5 women will experience an osteoporotic fracture in their lifetime [6]. The risk of re-fracture is greatest in the months following the first fracture, and the timely assessment and rapid treatment of subjects with fracture to prevent further fracture is an essential, established model [7].

How can we balance urgent resourcing of our acute crisis whilst not abandoning the real need of patients with osteoporosis? We propose rethinking the way we treat osteoporosis for the foreseeable future in the following ways: 


\section{Assessment of fracture risk}

With suspended DEXA services and advice that vulnerable people limit their exposure to clinical spaces, bone density assessment of patients with suspected osteoporosis will no longer be feasible in the near term. This will increase our reliance on fracture risk calculators that do not rely on bone density values, such as FRAX ${ }^{\circledR}[8,9]$. Fracture Liaison Services will need to consider fracture risk thresholds for their particular patient group to guide treatment initiation.

\section{Careful education of patients receiving intravenous bisphosphonates regarding flu-like reactions}

The risk of a flu-like reaction after an intravenous bisphosphonate infusion is substantial in treatment-naïve individuals and, in some studies, affected $>50 \%$ of individuals $[10,11]$. Strategies to reduce the risk of a flu-like reaction after IV bisphosphonates have variable success, and some groups may be more vulnerable than others. The possibility of an acute-phase reaction with fever and myalgia should be carefully discussed with patients, to avoid needless concern about this mimic of infection. The decision to use an intravenous bisphosphonate should consider the risk to patient or health-care worker posed by attendance at a healthcare facility (or even home) to access this therapy.

\section{Avoiding denosumab interruption}

Patients receiving long-term denosumab treatment may face a dilemma in weighing up the importance of receiving their treatment at regular 6-monthly intervals whilst also wishing to avoid attendance of their healthcare centre for the subcutaneous injection. Case series suggest that the risk of rebound increase in bone turnover and spontaneous vertebral fractures begins approximately 8 months following the last dose of denosumab [12], but this time interval may depend on a patient's duration of denosumab treatment, clinical course and baseline fracture risk [13]. We see a strong role for education programs for self-administration of denosumab, possibly in conjunction with Telehealth appointments. Patients receiving bisphosphonates should also be encouraged to continue treatment, bearing in mind the significantly greater risk of new fractures during drug intermission [14].

\section{Changes in therapy}

Decisions to escalate treatment, such as a switch from antiresorptive to an osteo-anabolic agent will be challenging in the current climate. Discussion of the benefits of such a change and demonstration of daily administration of agents such as teriparatide may require face-to-face clinical encounters. Patients may also wish to continue with their current treatment regimen in a time of uncertainty [15]. Decisions on bisphosphonate drug holidays may be guided by clinical judgement and, perhaps, bone turnover markers rather than DEXA measurement.

\section{Home-based exercise programs}

Patients with osteoporosis are advised to engage in regular weight-bearing exercise to improve their strength, balance, posture and reduce the risk of falls [16, 17]. With the advice to avoid large gatherings such as community centres or local gyms, hone-based exercise programs should be considered. Such programs have been shown to improve the quality of life of older individuals, may improve muscle mass and are feasible [18]. The prescription of a suitable home-based program would require a multidisciplinary approach between physician and allied health members.

\section{Generic advice to minimize risk of COVID-19}

Patients with osteoporosis are also likely to be at high risk from sequelae of contracting COVID-19. Telehealth consultations should take advantage of promoting regional-specific advice to minimize infection by social distancing and/or isolation where appropriate.

In the age of COVID-19, treatment of chronic diseases such as osteoporosis should not become an unintended casualty. Clinicians need to adapt to the challenges posed by this crisis and consider ways to continue serving the most vulnerable amongst us, those with chronic disease with their own substantive morbidity and mortality. For in a crisis, every little thing counts.

\section{References}

1. Hollander JE, Carr BG (2020) Virtually perfect? Telemedicine for Covid-19. N Engl J Med. https://doi.org/10.1056/NEJMp2003539

2. Schnell S, Friedman SM, Mendelson DA, Bingham KW, Kates SL (2010) The 1-year mortality of patients treated in a hip fracture program for elders. Geriatr Orthop Surg Rehabil 1(1):6-14 
3. Johnell O, Kanis JA (2006) An estimate of the worldwide prevalence and disability associated with osteoporotic fractures. Osteoporos Int 17(12):1726-1733

4. Johnell O, Kanis JA (2004) An estimate of the worldwide prevalence, mortality and disability associated with hip fracture. Osteoporos Int 15(11):897-902

5. Binkley N, Blank RD, Leslie WD, Lewiecki EM, Eisman JA, Bilezikian JP (2017) Osteoporosis in crisis: It's time to focus on fracture. J Bone Miner Res 32(7):1391-1394

6. Black DM, Rosen CJ (2016) Postmenopausal osteoporosis. N Engl J Med 374(21):2096-2097

7. Balasubramanian A, Zhang J, Chen L, Wenkert D, Daigle SG, Grauer A, Curtis JR (2019) Risk of subsequent fracture after prior fracture among older women. Osteoporos Int 30(1):79-92

8. Kanis JA, Harvey NC, Johansson H, Liu E, Vandenput L, Lorentzon M, Leslie WD, McCloskey EV (2020) A decade of FRAX: how has it changed the management of osteoporosis? Aging Clin Exp Res 32(2):187-196

9. Ahmed LA, Nguyen ND, Bjornerem A, Joakimsen RM, Jorgensen L, Stormer J et al (2014) External validation of the Garvan nomograms for predicting absolute fracture risk: the Tromso study. PLoS One 9(9):e107695

10. Popp AW, Senn R, Curkovic I, Senn C, Buffat H, Popp PF, Lippuner K (2017) Factors associated with acute-phase response of bisphosphonate-naive or pretreated women with osteoporosis receiving an intravenous first dose of zoledronate or ibandronate. Osteoporos Int 28(6): 1995-2002

11. Crotti C, Watts NB, De Santis M, Ceribelli A, Fabbriciani G, Cavaciocchi $\mathrm{F}$ et al (2018) Acute phase reactions after zoledronic acid infusion: protective role of 25-hydroxyvitamin $\mathrm{D}$ and previous Oral bisphosphonate therapy. Endocr Pract 24(5):405-410

12. Anastasilakis AD, Polyzos SA, Makras P, Aubry-Rozier B, Kaouri S, Lamy O (2017) Clinical features of 24 patients with rebound- associated vertebral fractures after denosumab discontinuation: systematic review and additional cases. J Bone Miner Res 32(6):12911296

13. Tsourdi E, Langdahl B, Cohen-Solal M, Aubry-Rozier B, Eriksen EF, Guanabens N et al (2017) Discontinuation of denosumab therapy for osteoporosis: a systematic review and position statement by ECTS. Bone. 105:11-17

14. Dennison EM, Cooper C, Kanis JA, Bruyere O, Silverman S, McCloskey E et al (2019) Fracture risk following intermission of osteoporosis therapy. Osteoporos Int 30(9):1733-1743

15. Barrionuevo P, Gionfriddo MR, Castaneda-Guarderas A, ZeballosPalacios C, Bora P, Mohammed K, Benkhadra K, Sarigianni M, Murad MH (2019) Women's values and preferences regarding osteoporosis treatments: a systematic review. J Clin Endocrinol Metab 104(5):1631-1636

16. Nanduri AP, Fullman S, Morell L, Buyske S, Wagner ML (2018) Pilot study for implementing an osteoporosis education and exercise program in an assisted living facility and senior community. $\mathrm{J}$ Appl Gerontol 37(6):745-762

17. Watson SL, Weeks BK, Weis LJ, Harding AT, Horan SA, Beck BR (2018) High-intensity resistance and impact training improves bone mineral density and physical function in postmenopausal women with osteopenia and osteoporosis: the LIFTMOR randomized controlled trial. J Bone Miner Res 33(2):211-220

18. Papaioannou A, Adachi JD, Winegard K, Ferko N, Parkinson W, Cook RJ, Webber C, McCartney N (2003) Efficacy of home-based exercise for improving quality of life among elderly women with symptomatic osteoporosis-related vertebral fractures. Osteoporos Int 14(8):677-682

Publisher's note Springer Nature remains neutral with regard to jurisdictional claims in published maps and institutional affiliations. 